\title{
Pros

\section{BLANCA VARELA Y EL GRAN AIRE DE LAS PALABRAS}

INÉS FERRERO CÁNDENAS

Universidad de Guanajuato inesferrerocandenas@gmail.com

RESUMEN: En este artículo señalo y reflexiono en torno a la idea de un pacto poético en la obra de la poeta peruana Blanca Varela (1926-2009). Este pacto lo llamo "el gran aire de las palabras", en referencia a uno de sus versos, e implica una actitud poética, un devenir en la palabra, un constante movimiento de la conciencia vareliana que, en mi opinión, constituye la piedra angular de su poesía. Mi trabajo articula el modo en el que este pacto comienza en su primer poemario, Este puerto existe (1959) y termina de cristalizarse en Ejercicios Materiales (1993) y en El libro de barro (1994). Para ello, tomo como referencia su poesía reunida en la antología Canto Villano, escogiendo sus versos a modo de antología personal y sin orden cronológico.

PALABRAS CLAVE: Blanca Varela; poesía hispanoamericana; poética

ABSTRACT: In this essay, I point and examine the idea of a poetic contract in the work of the Peruvian poet Blanca Varela (1926-2009). I will name this contract "el gran aire de las palabras" in reference to one of her poems, and it implies a poetic attitude, a becoming of the word, an incessant movement of the Varelian consciousness that, in my opinion, constitutes the cornerstone of her poetry. My work articulates the way in which this contract begins to take shape in her first poetry book, Este puerto existe (1959) and ends up crystallising in Ejercicios materiales (1993) and El libro de barro (1994). 
KeYwords: Blanca Varela; Latin-American Poetry; Poetics

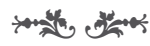

ella se desnuda en el paraíso

de su memoria

ella desconoce el feroz destino

de sus visiones

ella [NO] tiene miedo de no saber

nombrar

lo que no existe

Alejandra Pizarnik

Me hubiera gustado ver a Blanca Varela (Lima, 1926-2009) leer sus versos en público, ser uno de esos pocos que disfrutaron el privilegio de escuchar su voz. Especialmente hubiera querido escucharle decir: "no tiene sentido que yo esté aquí/ destruyendo/ lo que no existe" (1996: 167). Si bien no he tenido ese placer, voy a seguir rigurosamente el consejo de estos versos. Que no es otro que advertir, como hacía Paul Valéry, que no podemos decir casi nada sobre la poesía que no sea directamente inútil para aquellos que la desean. Porque todos los que la desean "sienten la necesidad de lo que comúnmente no sirve para nada, y perciben una especie de rigor en ciertas combinaciones de palabras completamente arbitrarias para otros oídos" (Valery 1990: 27; cursivas suyas). Intuyo que por esto mismo era inusual verla en lecturas poéticas. Incluso su exesposo, el pintor Fernando de Szyszlo, consideraba un raro privilegio verla en algún recital: "No recuerdo haberla escuchado leer sus poemas más de dos veces [...], pero cuando la he escuchado ha sido emocionante, porque es muy insegura, conmovida por lo que está leyendo" (Szyszlo en Hidalgo-Vega 2005: s.p.).

Los que conocieron a Blanca Varela la recuerdan como una persona tímida, solitaria, incluso renuente a publicar sus poemas. En su famoso prólogo, Octavio Paz recuerda las reuniones en los cafés parisinos de 1949, y cómo los que allí se juntaban no creían en el arte, pero sí en la eficacia de la palabra y en el poder del signo. ${ }^{1}$ Explica como la poesía era un acto de legítima defensa y que, por aquel entonces, todos cantaban. Y finalmente relata cómo "entre aquellos cantos, resaltaba el canto solitario de una muchacha peruana, Blanca Varela, por ser el canto más secreto y más tímido, el más natural" (Paz 1996: 9-10). Esta afirmación no deja de ser interesante. Aunque su canto resaltara entre los otros y a pesar de que es de las poetas más importantes del Perú, su obra no es muy conocida fuera de círculos literarios y académicos. Esto se debe a varios moti-

\footnotetext{
1 "En los cincuentas París la acogió. Casada en ese entonces con el artista plástico Fernando de Szyszlo, vivió intensamente la vida amorosa e intelectual de la ciudad. Fue en esa ciudad donde afianzó su personalidad. Eran los años de la posguerra, los intelectuales se reunían y el surrealismo andaba en boga. Blanca escribía sus Cantos" (Hidalgo-Vega 2005: s.p.).
} 
vos: a la ya mencionada timidez o parquedad social, a su renuencia a aparecer en público, a su desinterés por subrayar su nombre dentro de la ciudad letrada y a su silencio absoluto como poeta durante las décadas de los 70 y 80 . Quizás también se deba a que el reconocimiento internacional a su obra llegó tarde, pero seguro. En el 2001 ganó uno de los premios de poesía más importantes en México, el Premio Octavio Paz de Poesía y Ensayo; y en 2006 y 2007 obtuvo dos de los premios de poesía más prestigiosos de España: el Federico García Lorca² y el Reina Sofía, respectivamente. ${ }^{3}$

El recorrido poético de Blanca Varela es breve, intenso, y está recogido en ocho poemarios que abarcan los dos últimos siglos: Ese puerto existe (1959), Luz de día (1963), Valses y otras falsas confesiones (1972), Canto villano (1978), Ejercicios materiales (1993), El libro de barro (1993), Concierto animal (1999) y El falso teclado (2000). La crítica suele situarla dentro de la llamada generación del 50 en Perú, donde se incluyen poetas como Javier Sologuren, Sebastián Salazar Bondy y Jorge Eduardo Eielson. Con ellos comparte una suerte de surrealismo, si entendemos por este más una modalidad del espíritu que una estética específica. También compartió con esta generación la voluntad de poner la lírica en relieve dentro de un discurso de identidad nacional en el Perú. ${ }^{4}$ Pero exceptuando estos asuntos, la mayor parte de sus lectores coincide en que Varela no tiene una escuela definida (Paz 1996, Castañón 1996, Paoli 1996, Reisz 2008, Ortega 2001), que su desarrollo poético es inusual y singular, y que, si bien se pueden tender puentes con otros poetas o corrientes estéticas tales como el surrealismo o el modernismo, en realidad se aleja de cualquier maestro. ${ }^{5}$ Me refiero a asuntos temáticos, formales, pero sobre todo al ritmo, al fluir de su poesía.

\footnotetext{
${ }^{2}$ Mariela Dreyfus y Rocío Silva Santisteban abundan a este respecto: "Desde finales de los 70 y durante toda la década del 80, Blanca Varela calló por muchos años. Su parquedad poética se trastocó además en parquedad social: durante la década del 70 se dedicó trabajar como comentarista de libros en revistas como Amaru y como crítica de cine bajo el seudónimo Cosme en las páginas de La Prensa, sin participar activamente de la vida literaria limeña. A pesar de su opción clara por la huida del mundanal ruido de la ciudad letrada, hizo algunas excepciones y salió la palestra limeña para participar en algunos recitales colectivos como el que organizara el recordado poeta Césareo Martínez en el otrora Instituto Cultural Peruano-Soviético. Fueron a su vez años de trabajo constante como directora de la filial peruana del Fondo de Cultura y como presidenta de la sección peruana del PEN Club" (2007: 17).

${ }^{3}$ El premio Reina Sofía resultó en la elaboración de la antología Aunque cueste la noche, editada por la Universidad de Salamanca y a cargo de Eva Guerrero, autora del estudio introductorio. La selección poética fue realizada por el poeta Ángel González Quesada, y dicha selección es relevante en tanto que incluye algunos de los primeros poemas que Varela decidió suprimir de antologías posteriores, constituyendo un aporte fundamental para entender su obra.
}

${ }^{4}$ En 1949, Eielson, Bondy y Sologuren compilaron, editaron y publicaron la antología La poesía contemporánea del Perú, en donde participa Varela, y que de alguna manera obliga a repensar la poesía escrita en el Perú hasta entonces: "El programa estético de la antología está en el epígrafe:' 'sepultar en la sombra al árbol del bien y del mal, desterrar las honestidades tiránicas, para que dirijamos nuestro purísimo amor', de Arthur Rimbaud. Poco tomada en serio, la cita es es en sí misma una lección de cómo un epígrafe se debe a su relación con un programa estético y no al saqueo de un referente prestigioso. Tres son sus implicaciones: leer fuera de la conceptualización binomial y oposicional con que se imagina la cultura, leer fuera de la idea o convicción de que una cierta moral o ética validan o definen un programa artístico, y, finalmente, medir la poesía por las fuerzas con las que esta dirige un tipo de experiencia" (Herbozo 2016: s.p.).

${ }^{5}$ Es interesante la reflexión de Paz a este respecto: "En Blanca Varela hay una nota, común a casi todos los poetas de su tiempo, que no aparece en los de grupos anteriores, trátese de españoles, 
En el prólogo a la única antología crítica publicada hasta la fecha y dedicada en exclusivo a la obra de Varela, Nadie sabe mis cosas. Reflexiones en torno a la poesía de Blanca Varela (2007), ${ }^{6}$ Mariela Dreyfus y Rocío Silva Santisteban recorren la recepción crítica de la obra vareliana. En este recorrido podemos identificar tres grandes momentos críticos en su recepción, incluyendo la propia antología. El primero estaría exclusivamente marcado por el prólogo de Octavio Paz a Este puerto existe (1959); pero tiene lugar al mismo tiempo que el segundo. Me explico. Este fue un prólogo que, como bien apuntan Dreyfus y SilvaSantisteban, "no solo fue un 'espaldarazo' como han comentado algunos, sino que significó, como lo han señalado otros, una pauta de interpretación fuerte, un camino marcado para las exégesis posteriores, una ruta muchas veces difícil de desmarcar" (2007: 15). A grandes rasgos, Paz identifica tres itinerarios interpretativos en su obra. Primero, la conexión estética con el surrealismo, que a su vez dio lugar a la exploración de la presencia pictórica en su poesía por otros críticos (véase Suárez 2003, Rebaza 2007). ${ }^{7}$ Segundo, la invitación a deslindar la poesía de Varela de todo lo relacionado con "la femineidad", lo cual provocó otro derrotero de la crítica: la cuestión del género del autor en la producción poética y la diferencia entre lo "mujeril" y lo "femenino" (ver Reisz 2008). Y tercero, la noción de severidad o rigor expresivo en sus poemas. Respecto a esto último, Roberto Paoli considera que Varela es "ante todo fiel a su personal excavación, a su rigor ético que es, a la vez, una suerte de ascetismo estético. Se ha negado tanto a ensayar nuevas experiencias formales como a aceptar los códigos de la no-significación" (1996: 15).

El segundo momento de recepción crítica ocurre pocos años después de la publicación de Este puerto existe (1959); derivan hasta cierto punto del enfoque de Paz y constituyen los primeros artículos que profundizan sobre su obra. Para las autoras de la mencionada antología, "estos primeros ensayos críticos son textos fundacionales que significaron, para quienes vinimos después, puertas de entrada a la recepción de una poesía compleja, abstracta, aparentemente

\begin{abstract}
latinoamericanos o franceses. Los poetas de la generación anterior se sentían, por decirlo así, antes de la historia; los nuevos, después [...]. La poesía anterior a la guerra se propuso derribar el muro; la nueva pretende explorarlo, como se explora un continente desierto, una enfermedad, una prisión" (Paz 1996: 11; cursivas suyas).

${ }^{6}$ Comparto la visión de la mayor parte de los críticos que han reseñado este libro. Incluyo como ejemplo la opinión de Cecilia Esparza: "Este libro llena un vacío en la crítica literaria y será indispensable tanto para el medio académico como para el lector que se acerca a la obra de Varela con un interés distinto al profesional. La publicación reúne artículos especializados y enriquece nuestra comprensión de la obra y la vida de Blanca Varela a través de las entrevistas incluidas y lo que podríamos llamar una biografía ilustrada en las fotografías, casi todas inéditas, que nos acercan a momentos de su vida pública y privada. El texto contiene también una antología preparada por la propia Varela en el año 2005, una exhaustiva bibliografía y una cronología" (2008: 349).
\end{abstract}

7 Algunos críticos, como Modesta Suárez, atribuyen este interés por la pintura al hecho de que la poeta estuvo casada con el pintor Szyszlo durante su formación intelectual. La propia poeta comenta: "Algo formidable de vivir con Fernando ha sido el que me enseñara a ver la pintura -que es un arte que confieso me gusta más que la poesía. Hay en él un lado artesanal, sensorial, que envidio. Esta relación con la pintura está presentada de modo muy directo en un poema mío, 'Madonna', que es una descripción libre del famoso cuadro de Filippo Lippi" (Varela en Suárez 2003: 33). 
fácil pero de significaciones múltiples, densa y a veces, oscura" (Dreyfus y Silva Santisteban 2007: 15). Las compiladoras se están refiriendo a los trabajos de Octavio Paz, José Miguel Oviedo, Roberto Paoli, Ana María Gazzolo, James Higgins, David Sobrevilla, Américo Ferrari, Reynaldo Jiménez y Adolfo Castañón. Finalmente, el último momento de recepción crítica lo identifico con la publicación de esta misma antología en 2007. Esta última etapa (que engloba las anteriores porque en la antología también se incluye gran parte de los artículos y ensayos mencionados anteriormente) expande y profundiza sobre la recepción de la poesía de Varela, abarcando una gran pluralidad de perspectivas críticas que revisan y exceden las rutas marcadas por Paz y que abordarán, entre otras tendencias interpretativas, la identificación de genealogías familiares y "de la mirada", la severidad expresiva de su palabra, el discurso del modernismo, lo "criollo", los vasos comunicantes entre la pintura y la música, el simbolismo animal o la maternidad. La actitud de la crítica, si bien arriesgada en su súbita ansiedad por encerrar y abarcar esta obra, lo que sin duda demuestra es el lugar indiscutible de Blanca Varela dentro de la lírica hispanoamericana contemporánea. ${ }^{9}$

Tomaré como referencia para este trabajo la antología Canto Villano (1996), la primera recopilación de su obra poética, aunque ahora ya existan otras más completas. ${ }^{10}$ Sin embargo, no me voy a centrar en ningún poemario en específico, pues el objetivo de este artículo es señalar y reflexionar acerca de la idea de un pacto poético que atraviesa toda su producción lírica. A este pacto lo voy a nombrar "el gran aire de las palabras" en referencia a uno de sus versos, e implica una actitud poética de constante revisión, un devenir de su palabra, un decidido movimiento de la conciencia vareliana que, en mi opinión, constituye la piedra angular de su poesía. Más adelante explicaré las particularidades de este pacto. Por ahora basta decir que comienza en su primer poemario y termina de cristalizarse en Ejercicios Materiales y El libro de barro. Pienso que es en estos dos poemarios, ambos publicados en 1993, donde el pacto poético de Varela alcanza

8 Genealogía de la mirada es la expresión que utiliza Modesta Suárez para relacionar la obra de Varela con la pintura y la condición existencial del pintor. Las mujeres de la familia materna de Varela, eran grandes aficionadas a la pintura y a la música (2003: 35).

${ }^{9}$ A estas tres etapas cupiera añadir la publicación a comienzos de la década de los 80s de la antología Camino a Babel publicada por Javier Sologuren en las ediciones populares de la la Municipalidad de Lima: "El libro significó la difusión a nivel popular de una autora que, en ese entonces, comienzos de la dura década del 80, empezaba a considerarse como una poeta 'de culto' entre los poetas jóvenes y los estudiantes de literatura (Dreyfus y Silva-Santisteban 2007: 15). Finalmente también hay que añadir que en los últimos años muchos otros estudios se han unido a estos; y que también ha habido una considerable cantidad de tesis de grado y posgrado en diferentes universidades del mundo.

10 El motivo de esta elección, como se verá después, es porque esta antología culmina con El libro de barro. Efectivamente existen antologías más completas: En el 2001, la editorial catalana Galaxia Gutenberg publica el volumen Donde todo termina abre las alas. Poesía reunida (1949-2000), que reúne toda la producción poética de Varela hasta la fecha, incluyendo el conjunto inédito, El falso teclado. Esta edición consta además de un prólogo, "Blanca Varela: la poesía como conquista del silencio", de Adolfo Castañón, y un excelente epílogo del poeta Antonio Gamoneda, "Hablo con Blanca Varela". Muy recientemente, en el 2014, el sello editorial de la UNAM en México vuelve a recoger toda la producción de Varela en otro hermoso volumen, El suplicio comienza con la luz. Poesía Reunida (1949-200), en el que también se incluye un prólogo a modo de lectura dialogada de la poeta Rocío Silva Santisteban. 
su máxima nitidez y concreción. Es por eso que, aunque cito a Varela a modo de antología personal y sin orden cronológico, referiré a estos poemarios más frecuentemente, sin que esto implique, insisto, un análisis o reflexión en torno a los mismos.

En Este puerto existe, el yo lírico de Varela tiene voz masculina. Fue un rasgo que sorprendió mucho y que en parte provocó que Octavio Paz asumiera que no había nada menos femenino que la voz de Varela. Dicho atributo ha sido entendido generalmente por la crítica como un intento por comprender la universalidad de lo humano. Comparto no obstante con Julieta Gamboa que no se trata de esto, que más que la búsqueda de un sujeto universal, "la inexistencia de una marca de género explícita en este primer libro se debe a un momento originario de búsqueda de definición, a la expresión de una pregunta sobre cómo decir desde el lenguaje poético, hacia dónde ir, sin que haya respuestas definitivas" (Gamboa 2014: s.p.). Entonces, este no tener género se trata más bien de un experimento; de la primera y necesaria parte de su pacto poético: buscar sin perseguir un encuentro, una respuesta. Definir su propia voz a través de un sujeto poético y abstracto, quizás incluso divino. El experimento con el género no se vuelve a repetir. A partir de un segundo poemario y durante todos los siguientes, el yo lírico de Varela tiene cuerpo de mujer y lo cierto es que, como ya se ha comentado, buena parte de su recepción aborda la condición femenina como una de las marcas de su poesía.

Me resulta curioso que algunos de los mejores críticos de Varela hayan insistido sobre la dificultad de encontrar temas que atraviesen su obra. Roberto Paoli señala como "la dificultad de enuclear temas es corolario de su capacidad para reducir la complejidad de los elementos a la abstracción de una cifra" (1996: 18). Susana Reisz atribuye esta dificultad a la preferencia de Varela de "intensificar los registros más duros y recios para rechazar todo adorno verbal que evoque la servidumbre de los cosméticos" (2005: 45). Y digo que me resulta curioso porque no sé entonces si el tiempo, el cuerpo, lo instintivo, la muerte, la inexactitud divina o la pureza de la palabra se consideren temas o no por estos críticos, pero aun si no son temas, sí son preocupaciones centrales a su poesía. Más bien comparto con Silva Santisteban que "sus temas varían desde la experiencia mística (aunque distante y seca) hasta los diversos e insospechados retruécanos de la maternidad, pasando por la reflexión sobre el cuerpo y la muerte" (2013: 13). No tendré ocasión de discutir a profundidad dichos temas, pero quisiera mencionar que todos ellos engloban ideas, sentires y conceptos que participan de este pacto poético. Por otro lado, lo que sí es absolutamente cierto es que la voz de Varela no necesita de accesorios y siempre representa el devenir de una idea: "las cosas hablan entre ellas, se mueven hacia ellas mismas" (Varela 1996: 102). Quizás por eso a veces parece que su poesía escapa de todo tema, aunque esto sea prácticamente imposible.

En esta poesía se trata de "ver la carne convertida en paisaje" (Varela 1996: 203), de "convertir lo interior en exterior sin usar el cuchillo" (1996: 197), de acceder a ver la transmutación que permite el verbo y ser capaz de discernir que su búsqueda como poeta es el camino, que no se persigue el llegar sino el movimiento. Que no hay verdad, ni eternidad, porque "la verdad desaparece con 
la luz" (Varela: 1996: 206), y "es tan callada la voz de la verdad que es imposible oírla" (Varela: 1996: 206). Entonces, ¿en qué consiste este pacto poético, este "gran aire de las palabras"? El "gran aire" es aquello que no puede decirse pero que se dice. El "gran aire" es una lucha cuerpo a cuerpo con la palabra, es una inquietante dilucidación, es la divinidad de la palabra, su pureza o desnudez. Es también el instante del nacimiento del cuerpo poético. Es la necesidad de mirar en el otro lo que queremos sea mirado en nosotros mismos. Es la obligación de confrontar nuestro propio reflejo distorsionado. Es practicar, en palabras de Varela, el "Arte Negro: mirar sin ser visto a quien nos mira mirar" junto con el "Arte Blanca: cerrar los ojos y vernos" (1996: 184). El arte (magia) blanca y negra simbolizan a su vez la alquimia del verbo; y es así que la poesía de Varela se convierte en un prodigio de reconocimiento del yo a la vez que se define un yo plural. ${ }^{11}$ Esta pluralidad del ser poético funciona como un caleidoscopio y como una cámara lúcida. Es oscuro y resplandeciente. La poeta tiene que comunicar sin ser sometida a la incitación del afuera. Lo que se tiene que nombrar obedece a una pulsación interior. Encierra en sí el misterio de lo correcto, de lo expresable y también de lo que considera indecible: "Junto al pozo llegué/ mi ojo pequeño y triste/ se hizo hondo, interior./ Estuve junto a mí/ llena de mí, ascendente y profunda,/ mi alma contra mí,/ golpeando mi piel,/ hundiéndola en el aire, hasta el fin./ La oscura charca abierta por la luz./ Éramos una sola criatura,/ perfecta ,ilimitada,/ sin extremos para que el amor pudiera asirse./ Sin nidos y sin tierra para el mando" (1996: 50).

La pulsación creativa, la insatisfacción, la búsqueda de la perfección, la incertidumbre, el cuerpo, todos impulsan estos versos de Varela. Leemos una voz que sabe salir de su soledad para buscarse desesperadamente, para comunicar su propio misterio. Su propio secreto. Y aun cuando no haya secreto que anunciar, la poeta queda con un disimulo aparente y burlón: "Y te rendimos diosa/ el gran homenaje/ el mayor asombro/ el bostezo" (1996: 147). Varela asevera la dificultad en la comunicación del secreto que se descubre, o del secreto que habita perspicaz en la lucha constante del intentar nombrar: "Un poema/ como una gran batalla/ me arroja en esta arena/ sin más enemigo que yo/ yo/ y el gran aire de las palabras" (1996: 123; mis cursivas). La poeta es consciente del carácter inasible de la palabra, y aun así, no puede sino conjurarla. Escribir es batalla pero también es goce, riesgo absoluto, pues es instalarse en ese aire, y en el caso de la peruana, es instalarse con todo el cuerpo, con toda su humanidad y animalidad. "En el aire escribo/ con mi lengua escribo/ con mis manos y pies escribo/ con mis ojos" (1996: 133). Quizás por eso su palabra esté tan alejada del "artificio de los cosméticos" (Reisz 2005: 45). Despojada de toda máscara, arde sobre su cuerpo: "entre mis dedos/ ardió el ángel" (1996: 146) y después "el justo golpe/ la mano/ la música de la mano/ la rebusca en el fuego" (1996: 152). Estas citas pertenecen a dos poemas diferentes de Canto Villano. En este poemario la palabra de Varela es más breve y rigurosa que nunca. La poeta rechaza fervientemente la

11 En este sentido, su poesía también participa de una de las preocupaciones centrales de la poesía simbolista. Estoy pensando en la "Alquimia del verbo" de Rimbaud, en el desarreglo de los sentidos que producen las sinestesias y también en el famoso Je est un autre. 
rosa simbólica de la poesía, que aquí se convierte en "la detestable perfección/ de lo efímero/ infesta la poesía/ con su arcaico perfume" (1996: 20). El combate contra el "gran aire" rechaza la perfección y abraza la inexactitud, el arte poética es un juego incendiario y carnal: "puedes contarme cualquier cosa/ creer no es importante/ lo que importa es que el aire mueva tus labios/ o que tus labios muevan el aire/ que fabules tu historia tu cuerpo/ a toda hora sin tregua/ como una llama que a nada se parece/ sino a una llama" (1996: 127). Igual que creer no es importante, aquel refrán que asegura que "ver es creer" es negado en su poesía, no importan los objetos, sus colores, importa el espacio poético en el que estos resuenan. La creación de este espacio es la culminación del pacto: "y el color no tiene en realidad importancia/ sino el espacio en que una inmensa flor sin nombre se mueve/ el espacio lleno de un esplendor sin nombre/ y mis ojos, fijos, sin nombre" (1996: 128).

Esta poesía es un canto incandescente pero escéptico. Escéptico porque en su búsqueda de la palabra pura se aprecia una ausencia. Julieta Gamboa señala cómo "los poemas llegan a ser un canto, pero no festivo, sino áspero, que nombra la falta. La voz poética encuentra una constante: el desconcierto, la incomodidad ante la realidad, la imposibilidad de que el lenguaje poético otorgue sentidos" (2014: s.p.). Las palabras de Varela no tratan de explicar la posibilidad del mundo, ni tampoco del poema. No se trata de comprender ni de declarar. Se trata de que el mundo se queme en el poema, o mejor, que el poema incendie al mundo: "todas las riquezas, todas las miserias, todos los hombres, todas las cosas desaparecen en esa melodía ardiente" (1996: 139). Como dice Paz, su poesía no razona, no explica, no confiesa, es "un signo, un conjuro frente, contra y hacia el mundo, una piedra negra tatuada por el fuego y la sal, el amor, el tiempo y la soledad. Y también, una exploración de la propia conciencia" (1996: 10). Por eso mismo no se trata de razonar sino de palpar, de percibir, de imaginar. No hay que explicar, sino escuchar aguzando la sensibilidad. No se trata de confesar, solo de sentir las correspondencias: "palpar la imagen, escuchar la sangre. Oír su sagrado perfume" (1996: 223).

¿No son los poetas hechiceros que conjuran palabras nuevas para describir las nubes, las piedras, las manos? Al escribir se genera ese instante en el que las cosas no son aún y a la vez están siendo, cosas que pierden el nombre y regalan su esencia para ser renovadas a través de una conciencia imaginante: "Sentimos algo dentro y algo en torno y todo lo que fuimos y seremos por un instante cabe en nuestros labios, bocado de ceniza que ilumina, gusto de tierra amargamente viva, quemadura de sal de mar en que se nace./ Todo cabe en dos ojos deslumbrados, todo el color en un violento despertar en una plaza, a solas" (1996: 80). Es en ese "sentir adentro", en ese eterno instante, en su soledad, donde más se percibe el escepticismo, el desengaño de la voz poética que siente el vacío de lo divino o de un ente absoluto que se comunique: "Contemplamos el cielo/ no hay señales" (1996: 68). La falta de indicios, de alguien que se comunique, conduce a una oscura soledad. Esta es sin duda la causante de la destilación alquímica de su palabra, la que provoca su máxima concreción y desnudez. Y a su vez, también es el lazo con la materialidad del cuerpo: "despertar/ en la gran palma de dios / calva vacía sin extremos / y allí te encuentras / sola y perdida en 
tu alma/ sin más obstáculo que tu cuerpo/ sin más puerta que tu cuerpo" (1996: 192). En una entrevista a Rosina Valcárcel, Varela habla precisamente de la productividad de la soledad: "siempre he sido bastante solitaria", dice, "y además [...] yo creo que no me sentía sola en absoluto. La sordera de Dios es evidente, hasta hoy la siento" (2007: 455). La peruana afirma que si no hay comunicación con algo trascendente solo queda la posibilidad de internarse en uno mismo, de enfrentar su propio demonio, el espejo, la cópula. Y continúa: "La poesía sigue siendo para mi una manera de seguir explorando, de darles nombre a los demonios [...]. Por eso a veces mis grandes silencios en poesía" (1996: 455).

Ejercicios materiales, un título que alude visiblemente a las reglas de preparación espiritual de Ignacio de Loyola, se emplea aquí para presentar una regla profana. Se trata de las enseñanzas de la Diosa Oculta, la propia poesía, y son en efecto ejercicios para enfrentarse a sus demonios, al vacío, a la sordera del dios que sí escuchaba Loyola pero que Varela no podía escuchar, o al menos no de la misma manera. Ejercicios materiales para que la palabra no se fugue ni se haga polvo, "polvo rebelde sí/ con los cabellos de polvo desordenado/ para siempre jamás por un peregrino pensamiento/ [...], palabra escrita palabra borrada/ palabra desterrada/ voz arrojada del paraíso/ catástrofe en el cielo de la página/ hinchada de silencios" (1996: 185). El pacto poético de Varela consiste en aceptar esa realidad absurda e inexacta, y por supuesto, de revisarla a través de la palabra poética. En eso consiste también la soledad, la orfandad: en la imposibilidad de otorgar un sentido. Lo que se busca no se encuentra, lo que se encuentra no se puede atrapar y lo que se nombra se desvanece en su enunciación. La palabra fluye centrífuga: "Un círculo en el aire para atrapar algo de lo perdido./ El sueño de ayer, la imagen que se escapa entre dos aguas, que se multiplica y transforma hasta no ser sino el agua misma, el brillo deslumbrante, instantáneo, de los propios deseos" (1996: 81). ¿El poema nombra y logra ser? La voz poética de Varela persigue una sagrada inexactitud y también es ahí donde la poesía se vuelve metafísica, donde "el ojo comienza a desteñirse/ a no ser/ y la voz se quiebra inaudita/ (alguien ha perdido definitivamente su balsa)" (1996: 186).

Escuchamos una voz a la deriva, indiferente, que entona el amanecer de un nuevo día y canta el paso implacable del tiempo. Un tiempo que actúa sobre la carne, sobre el cuerpo, que confabula presencias e invisibilidades. "Dime/ ¿durará este asombro?/ ¿esta letra carnal/ loco círculo de dolor atado al labio/ esta diaria catástrofe/ esta maloliente dorada callejuela sin comienzo ni fin/ este mercado donde la muerte enjoya las esquinas/ con plata corrompida y estériles estrellas?" (1996: 121). Su fe, su pacto poético, apunta a un movimiento de la conciencia que siente el tiempo como una herida que crece: "de lo inexacto me alimento/ y toda el agua de los cielos es incapaz de lavar esta ínfima y rebelde herida de tiempo que soy" (1996: 185). Es una voz que afirma que "no se retorna de ningún lugar" (1996: 193), que sabe que si hay otro lado, es igual a este: "Al otro lado de la ventana/ alguien ha resuelto el enigma/ para entrar en la vida solo hace falta una puerta" (1996: 187). Se anuncia que no hay vida sin cuerpo y que este es una casa de cuervos. Por eso así siempre, al final, "otra vez este prado/ este prado de negro fuego abandonado/ otra vez esta casa vacía/ que es mi cuerpo/ adonde no has de volver" (1996: 192). 
La lucha entre el cuerpo del poema y su propio cuerpo refleja una sabiduría que como bien dice Adolfo Castañón, recuerda a la de Heráclito citado por Zambrano, es decir, una sabiduría que "reparte el logos por todas las entrañas" (Castañón 1996: 38). Y sí, la voz se auto-inmola, el yo lírico se ofrenda en el altar del lenguaje. La mujer transita con su sombra por el espejo y con su reflejo ante los otros. Se despoja de esta sombra, de este reflejo, y no se rinde. Sigue luchando: "Defenderse del incendio con un hacha. Del demonio con un hacha, de dios con un hacha./ Del espíritu y la carne con un hacha" (1996: 194). En tal disputa de la carne con el lenguaje, el ojo, la nariz y la boca se despojan de sus colores. Ya dijimos que el color no importa sino el aire que lo mueve. Como continúa diciendo Castañón, Varela enuncia desde un misticismo ateo "fundado en el oficio desnudo de una palabra desnuda" (1996: 36). Y añado, impresa sobre su cuerpo: "así caídos para siempre/ abrimos lentamente las piernas/ para contemplar bizqueando/ el gran ojo de la vida/ lo único realmente húmedo y misterioso de nuestra existencia/ el gran pozo/ el ascenso a la santidad/ el lugar de los hechos" (1996: 199). Este baile de caída también anuncia, claro está, la elevación de la palabra poética, su relación con lo divino: "entonces/ no antes ni después/ se empieza a hablar con lengua de ángel/ y la palabra se vuelve digerible" (1996: 201).

En esto consiste entonces el "gran aire de las palabras": en obtener el lenguaje silencioso a través de una pauta profana y sin adornos. Esta pauta involucra una alquimia verbal, una destilación. Implica reconciliarse con o luchar contra, sus propias expresiones. Hay que rehacerlas, transmutarlas o destruirlas completamente. Por eso, insisto, este pacto atraviesa toda su obra. Entonces, el silencio no es un no decir, sino una contención para evitar el desborde. Del silencio deriva la poiesis, esto es, del entusiasmo por lidiar con un conflicto que rebasa la expresión. Esta es, en cierto sentido, la misión mística de la escritura. Aunque la regla de Varela sea profana. Su misticismo incorpora una fe total en la incertidumbre, en la ausencia, en la falta. "Mirando a los dioses borrarse en el muro y a los hombres sangrar en el libro de barro. Sal en los labios y en los ojos la memoria desollada aproximándose a la ausencia ejemplar" (1996: 221). O también: "Hablando. Soy el dios de un cielo vacío como un huevo vacío. Mi piel el revés del cascarón donde la vida ardía" (1996: 222). La voz poética expresa un entusiasmo por lo abierto e inexacto que no obedece a ninguna doctrina pero que llama al fuego sagrado. Alejandra Pizarnik decía que "el lenguaje silencioso engendra fuego" (1996: 553) y en el caso de Varela se diría que el lenguaje fogoso engendra vacío: "es el día sobreviviente con su carreta vacía/ sigue brillando la lámpara penitente/ pero no creo en su luz/ ni compro la muerte con nombre de pez/ ni es cierto que bajo su escama mortecina/ dios nos contempla" (1996: 186).

Al yo lírico le incomoda la realidad porque es temporal, porque la ausencia de "lo trascendental" que se comunique descubre una nada impasible: "No habrá testigos/ se nos ha advertido que el cielo es mudo" (1996: 194). De ahí que surja la necesidad de batallar contra el gran aire, para que "alguien vuelva/ desvelado y sin prisa/ con un triángulo de eternidad entre las manos" (1996: 189). Aun invocándola, la poeta no se deja engañar por la eternidad. Al contrario, llamar su nombre presupone un exorcismo. Tiene así una voz que "se sabe callar a tiempo" (Paz 1996: 12). Es una voz devoradora de dios. Es más, hace a dios 
"aplastable/ perecible/ digerible" (1996: 201). El pacto poético de Varela nace de un acto de legítima defensa, de su camino a través del espejo, del incendio del yo. Su poesía es una prueba de que más allá del nombrar existe una ruta: "he dejado la puerta entreabierta/ soy un animal que no se resigna a morir" (1996: 39). Como dice Adolfo Castañón, "a diferencia de la imaginación cristiana que postula un infinito número de moradas en el Reino, en la creación de Blanca Varela solo hay una pero infinita" (1996: 37). "Un hogar seguro en el desierto. La sólida casa de la duda no tiene paredes. Se llama así. Solamente casa. Solamente desierto. Corral a la intemperie, noche infinita en la sentina del tiempo" (1996: 213). Esta fe en lo incierto, me aventuro a concluir, es la causante de esta expresión poética importuna, directa, perseverante, consciente de las trampas del lenguaje: "miente la nube/ la luz miente/ los ojos/ los engañados de siempre/ no se cansan de tanta fábula" (1996: 124). La sólida creencia en la mentira, en el disfraz de la palabra, en la ficción, otorga a las palabras de Varela un halo de orfandad amorosa, no angustiada, un hambre por lo material, un deseo de goce: "este hambre propio/ existe/ es la gana del alma/ que es el cuerpo/ es la rosa de grasa/ que envejece/ en su cielo de carne [...] no hay otro aquí/ en este plato vacío/ sino yo/ devorando mis ojos/ y los tuyos" (1996: 155). Lo suyo no es crucifixión, sino "cruci-ficción" (1996: 158). Y ahí, dios, cristo, no tiene "ni una línea para asirse/ ni un punto/ ni una letra/ ni una cagada de mosca/ en donde reclinar la cabeza" (1996: 158). El "gran aire de las palabras" consiste en que la poesía perpetúe un movimiento. Que este fluir poético sea la extensión de una conciencia que solo tiene una certeza: la mentira. Es entonces la de Blanca Varela una sabiduría que versa sobre la palabra cantada en movimiento, que trasciende o se desvanece, como los pensamientos, como dios, como el instante, como el cuerpo: "Seguridad de lo cambiante. Columnas de polvo sostienen el cielo de la tarde. Desaparecen como un pensamiento demasiado intenso para durar. Eternidad circular. Evasiva [...]. Los días son iguales, las horas no. Calidades del tiempo inagotable y escaso. Uno y ninguno [...]. Hallar el frágil huesecillo de la estirpe al azar y perderlo" (1996: 218).

\section{OBRAS CITADAS}

Castañón, Adolfo (1996): "Blanca Varela: la piedad incandescente". En: Blanca Varela, Canto Villano. Poesía Reunida. 1949-1994. México, FCE, pp. 25-43.

Dreyfus, Mariela, y Silva Santisteban, Rocío (eds.) (2007): Nadie sabe mis cosas. Reflexiones en torno a la poesía de Blanca Varela. Lima, Fondo Editorial del Congreso del Perú.

Esparza, Cecilia (2008): "Reseña a Nadie sabe mis cosas. Reflexiones en torno a la poesía de Blanca Varela", Lexis, vol. xxxII, n. ${ }^{\circ} 2$, pp. 349-354.

Franco, Jean (2008): "Blanca Varela y el animal interior", Revista de Crítica Literaria Latinoamericana, vol. 34, n. ${ }^{\circ}$ 67. pp. 325-328.

Gamboa, Julieta (2014): "El hombre es un extraño animal", Confabulario. El Universal. Accesible en <http://confabulario.eluniversal.com.mx/cimientos-2/> [última consulta: 10.09.2015].

Gamoneda, Antonio (2001): "Hablo con Blanca Varela". Epílogo a Blanca Varela, Donde todo 
termina abre las alas. Barcelona, Círculo de Lectores / Galaxia Gutenberg.

Herbozo, Miguel (2016): "La poesía contemporánea del Perú, antología de Jorge Eduardo Eielson, Sebastian Salazar Bondy y Javier Sologuren", Cuadernos del Hontanar. Accesible en <https://cuadernosdelhontanar.com/2016/02/01/la-poesia-contemporanea-del-peru-1946-antologia-de-jorge-eduardo-eielson-sebastian-salazarbondy-y-javier-sologuren/> [última consulta: 10.09.2015].

Hidalgo-Vega, David (2005): "El libro de barro y otros poemas de Blanca Varela: Una poeta en carne viva". El Comercio (Lima). Accesible en <http://www.letras.s5.com/ bv280905.html> [última consulta: 10.09.2015].

O'Hara, Edgar (2007): Tiene más de avispero la casa. Poéticas de Blanca Varela. Salamanca, Universidad de Salamanca.

Ortega, Julio (2001): "Blanca Varela: una verdad en carne propia", La Gaceta del Fondo de Cultura Económica, n. ${ }^{\circ}$ 365, p. 14.

Paoli, Roberto (1996): "Una visión lúcida y desencantada". En: Blanca Varela, Canto Villano. Poesía Reunida. 1949-1994. México, FCE, pp. 15-25.

Paz, Octavio (1996): "'Destiempos' de Blanca Varela". En: Blanca Varela, Canto Villano. Poesía Reunida. 1949-1994. México, FCE, pp. 7-15.

Pizarnik, Alejandra (2005): Poesía Completa. Buenos Aires, Lumen.

Reisz, Susana (2005): "Blanca Varela en la línea mortal del equilibrio", Clarín: Revista de nueva literatura, año 10, n. ${ }^{\circ} 60$, pp. 10-14.

Rebaza-Soraluz, Luis (2007): "El artista contemporáneo y el 'drama' de la disposición poético-plástica del espacio peruano: Sebastián Salazar Bondy, Blanca Varela y Jorge Eduardo Eielson". En: Mariela Dreyfus y Rocío Silva-Santisteban (eds.), Nadie sabe mis cosas: reflexiones en torno a la poesía de Blanca Varela. Lima, Fondo Editorial del Congreso del Perú, pp. 181-197.

Rodríguez Gutiérrez, Milena (2008): "La metáfora animal: en torno al bestiario de Blanca Varela", Revista de Crítica Literaria Latinoamericana, vol. 34, n. ${ }^{\circ}$ 68, pp. 211-223.

Silva-Santisteban, Rocío (2001): "Blanca Varela: aprender a ver en la doblez". En: El suplicio comienza con la luz. Blanca Varela. Poesía Reunida 1949-2000. México, UNAM.

Suárez, Modesta (2003): Espacio pictórico y espacio poético en la obra de Blanca Varela. Madrid, Verbum.

Valcárcel, Rosina (2007): "Blanca Varela: Esto es lo que me ha tocado vivir". En: Mariela Dreyfus y Rocío Silva Santisteban (eds.), Nadie sabe mis cosas. Reflexiones en torno a la poesía de Blanca Varela. Lima, Fondo Editorial del Congreso del Perú, pp. 445446.

Valéry, Paul (1990): Teoría, poética y estética. Trad. Carmen Santos. Madrid, La balsa de la Medusa / Visor.

Varela, Blanca (1994a): "La poesía es una sola". (Entrevista a Blanca Varela, parte 1), Diario La República (suplemento "Domingo"), 15 de mayo, pp. 25-26.

—_ (1994b): "Prefiero la desvergüenza". (Entrevista a Blanca Varela, parte 2), Diario La República (suplemento "Domingo"), 22 de mayo, pp. 35-36.

(1996) Canto Villano. Poesía Reunida. 1949-1994. México, FCE.

Varela, Blanca; Guerrero-Guerrero, Eva; González-Quesada, Ángel (2007): Aunque cueste la noche. Salamanca, Universidad de Salamanca. 